\title{
Antioxidant Function and Health Implications of Vitamin E
}

\author{
Ching Kuang Chow*,1 and Hannah S Chow-Johnson ${ }^{2}$
}

\author{
${ }^{1}$ Department of Dietetics and Human Nutrition, and Graduate Center for Nutritional Sciences, University of Kentucky, \\ Lexington, KY 40506-0054, USA \\ ${ }^{2}$ Department of Pediatrics, Loyola University Medical Center, North Riverside, IL 60154, USA
}

\begin{abstract}
Superoxide, a key precursor of important reactive oxygen/nitrogen species (ROS/RNS), may release iron from its protein complex. By mediating the generation and/level of superoxide, vitamin $\mathrm{E}$, the most important fat-soluble antioxidant and free radical scavenger, may exert its antioxidant function by limiting the formation of reactive hydroxyl radicals and peroxynitrite. The antioxidant function of vitamin $\mathrm{E}$ is augmented by GSH peroxidase and related metabolic systems which respond adaptively and compensatively to oxidative stress. By mediating the levels of ROS/RNS, vitamin E may also modulate the activation and/or expression of redox-sensitive biological response modifiers, and thereby attenuate the cellular events leading to the onset and development of aging and other degenerative disorders. Earlier epidemiological data and retrospective studies show an association between increased intake of vitamin $\mathrm{E}$ and reduced risk of cardiovascular disease, cancer, and other disorders. However, subsequent prospective randomized placebo-controlled studies and interventional trials have provided inconsistent findings. Data available from recent large-scale interventional trials suggest that vitamin E supplements at high doses are not beneficial.
\end{abstract}

Keywords: Vitamin E, tocopherols, superoxide, biological function, health benefit.

\section{INTRODUCTION}

Vitamin E is referred to all tocol (tocopherol) and tocotrienol derivatives qualitatively exhibiting the biological activity of RRR- $\alpha$-tocopherol. There are four tocopherols $(\alpha-, \beta-, \gamma-$ and $\delta$-) and four tocotrienols $(\alpha-, \beta-, \gamma-$ and $\delta$-) that occur naturally, differing in the number and position of methyl groups on the chroman ring [1,2]. Vitamin E was discovered 90 years ago, and a number of species-dependent and organ-specific deficiency symptoms of vitamin $\mathrm{E}$ were reported later [3,4]. However, due to the lack of clinically defined deficient syndromes attributable to vitamin $\mathrm{E}$ and the difficult to produce vitamin E deficiency in adults, its essentiality for humans was established only after the discovery of $\alpha$-tocopherol transfer protein decades later $[2,5-8]$. The transfer protein binds RRR- $\alpha$-tocopherol preferentially over other forms/isomers of tocopherols, and enhances its transfer and return to the liver. The presence of $\alpha$-tocopherol transfer protein is largely responsible for higher biological activity of RRR- $\alpha$-form than other forms/isomers.

Data obtained from experimental animal studies suggest a role of free radical-induced oxidative damage in the pathogenesis of aging and chronic diseases, and a possible prevention of the disease process by vitamin $\mathrm{E}$ and other antioxidants $[2,9]$. However, how does vitamin E exert its protective action against oxidative tissue damage is not entirely clear. In the $80 \mathrm{~s}$, the interest in vitamin $\mathrm{E}$ was

"Address correspondence to this author at the Department of Dietetics and Human Nutrition, and Graduate Center for Nutritional Sciences, University of Kentucky, Lexington, KY 40506-0054, USA; Tel: 1-859-257-7783; Fax: 1-859-257-3707; E-mail: ckchow@uky.edu promoted by a number of observational and retrospective studies which show a higher vitamin $\mathrm{E}$ intake is associated with a lower risk of cardiovascular disease and cancer. However, the findings obtained from subsequent prospective, randomized, placebo-controlled trials do not show a consistent benefit [10-17]. Moreover, results obtained from recent large scale intervention trials suggest that vitamin E supplement at high dose may even be harmful. This article is intended to provide a rational view as to how vitamin E may exert its antioxidant and other biological functions, and to address the possible health implications of vitamin $\mathrm{E}$ supplement. The first part of this article, role of vitamin $\mathrm{E}$ in cellular antioxidant defense, is updated from the one appeared previously [18].

\section{ROLE OF VITAMIN E IN CELLULAR ANTIOXI- DANT DEFENSE}

While a number of factors may initiate or enhance oxidative stress, many antioxidant systems present may prevent harmful effects of oxidative stress $[9,19]$. However, oxidative damage may still result from excess oxidative stress, inadequate antioxidant potential, and/or the combination of the both. Vitamin E is the most important lipid-soluble antioxidant/free radical scavenger, and may react with peroxyl radicals much faster than with acyl lipids [2,9]. The earlier debate concerning whether vitamin $\mathrm{E}$ is essential or needed for human is partly caused by the lack of experimental evidence concerning the antioxidant function of the vitamin.

Lipid hydroperoxides are highly toxic to experimental animals when administered intravenously, but not orally. 
Lipid hydroperoxides is expected to increase when dietary vitamin E, the major fat soluble antioxidant, is depleted. However, no significant lipid hydroperoxides is accumulated in the tissues of oxidatively stressed animals $[2,9,19]$. Thus, there must be a pathway or system capable of metabolizing lipid hydroperoxides formed. In a pioneer study to test this hypothesis, rats maintained in a basal vitamin E-deficient diet supplemented with, either $0,10,45,150$ or $1500 \mathrm{IU} / \mathrm{kg}$ vitamin E, for 5 weeks were exposed to either ambient room air or 0.7 ppm ozone for 5 days or 0.8 ppm ozone for 7 days. The levels of lipid peroxidation products and activities of GSH peroxidase and metabolically related enzymes were found to increase significantly in the lungs of ozone-exposed rats [20]. Also, dietary vitamin $\mathrm{E}$ was found to dosedependently decrease the activities of GSH peroxidase and related enzymes [20,21]. Additionally, the level of GSH and activities of the GSH peroxidase system were significantly higher in the lung of ozone-tolerant rats than that of the controls [22], and the activities of pentose shunt and glycolytic enzymes were also increased in lungs of ozone-exposed rats [23]. These findings suggest that GSH peroxidase and other metabolic systems may respond to oxidative stress adaptively, and complement the antioxidant function of vitamin E. It may also be responsible for the lack of accumulation of lipid hydroperoxides in animal tissues [9,18,21,23,24].

In addition to the GSH peroxidase system which complement the antioxidant function of vitamin E, a number of reducing agents, including GSH and ascorbic acid, may regenerate or restore vitamin E [9,25-27]. Thus, coupled with the adaptive response of metabolic activities to oxidative stress, the ability of vitamin E to regenerate or recycle provides a rational explanation as to why there is no widespread vitamin $\mathrm{E}$ deficiency in humans, and why it is difficult to produce vitamin $\mathrm{E}$ deficiency in human adults.

\section{HOW MAY VITAMIN E PROTECT AGAINST OXI- DATIVE DAMAGE?}

Vitamin $\mathrm{E}$ is recognized as the most important antioxidant, and its antioxidant function in vivo is supported by a large number of experimental studies [2,9]. However, the antioxidant oxidant function alone does not adequately explain all the biochemical and pathological abnormalities observed, and other roles of the vitamin have been proposed $[28,29]$. Nevertheless, information available support the major function of vitamin $\mathrm{E}$ as an antioxidant at physiological concentrations [30,31].

Increased levels of ROS/RNS may lead to degradation and/or inactivation of essential cellular constituents [32-34]. Superoxide, hydrogen peroxide, nitric oxide and peroxyl radicals are the most significant ROS/RNS found in aerobic environment [35-37]. Mitochondrion, which utilizes the majority of oxygen, is the major source of superoxide [36-38] and has the highest concentration of vitamin $\mathrm{E}$ in the inner membrane [39]. Interestingly, mitochondrial ultra-structure change in the skeletal muscle is one of the earliest events found in vitamin E-deficient rats [40]. Also, vitamin E deficiency markedly increases de novo synthesis of xanthine oxidase in the skeletal muscle of vitamin E-deficient rabbits [41], and increases the enzyme activity in the liver of vitamin E-deficient rats [42]. The results obtained from these studies suggest an increased mitochondrial superoxide generation and a role of the ROS/RNS in the pathogenesis during vitamin E-deficiency.

In a study to determine the effect of vitamin $\mathrm{E}$ on mitochondrial ROS/RNS generation, dietary vitamin $\mathrm{E}$ was found to dose dependently decrease rates of mitochondrial hydrogen peroxide generation in liver and skeletal muscle of both male and female rats [43]. Similarly, the rate of superoxide generation by submitochondrial particles was found to inversely related to the vitamin E content in skeletal muscle, liver, and kidney of mice [44]. These findings suggest that dietary vitamin $\mathrm{E}$ may mediate the generation and/or level of superoxide and related ROS/RNS via maintaining mitochondrial integrity and stability, mediating the superoxide generation systems, and/or scavenging superoxide generated $[43,45]$.

Superoxide can react readily with nitric oxide to form highly reactive peroxynitrite [35], and hydroxyl radical may be formed from superoxide and/or hydrogen peroxide in the presence of labile iron or available form of iron [46-50]. Essentially all iron and copper are normally transported and stored as protein complexes, and are not available to catalyze the formation of the hydroxyl radicals. However, the state and levels of available iron or copper may be altered by oxidants or reductants, including superoxide and hydrogen peroxide, acting on cell iron sources [51-53].

As vitamin $\mathrm{E}$ may attenuate iron-induced oxidative damage $[54,55]$, whether dietary vitamin $E$ alters labile iron content and oxidative damage were examined in rats. The results show that dietary vitamin E dose-dependently decreases the levels of labile iron and lipid peroxidatiojn products in tissues of both male and female rats [56]. These findings collaborate well the view that superoxide plays an important role in oxidative damage, and that vitamin $\mathrm{E}$ may protect against oxidative damage by attenuating the generation and/or levels of superoxide and labile iron (Fig. 1). The ability of vitamin $\mathrm{E}$ to limit the generation and/or level of superoxide, which in turn attenuate the formation of reactive hydroxyl radical and peroxynitrite, is likely the key feature of its antioxidant function.

As ROS/RNS may alter the expression and activation of vital biological modifiers, intracellular production/level of ROS/RNS may alter cell proliferation, differentiation, apoptosis, and other vital cellular events [57-64]. Thus, by mediating the generation and/or levels of ROS/RNS, dietary vitamin E may modulate the activation and/or expression of redox-sensitive biological response modifiers, and thereby attenuates the cellular events leading to the onset of aging, cardiovascular disease, cancer, and neurodegenerative diseases (Fig. 1). However, whether the modulating role of vitamin $\mathrm{E}$ in the cell-signaling events is secondary to its antioxidant function remains to be elucidated. Also, ROS/RNS do not necessary leading to random deleterious modification of macromolecules with an associated progressive development of age associated systemic disease, and may serve as regulated prooxidant second messenger systems, with specific sub-cellular locales of production and are essential for normal metabolome and physiological function [65]. 


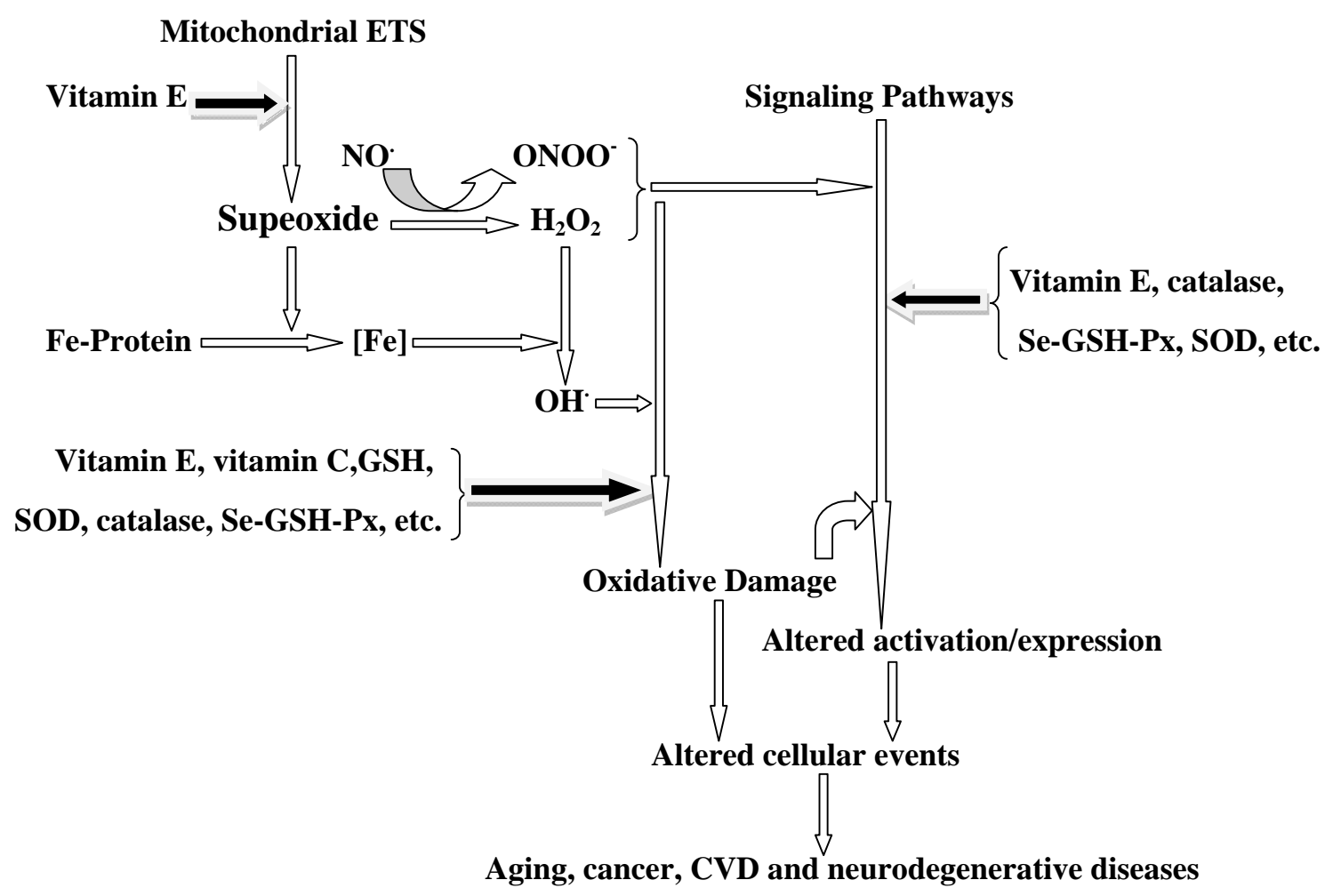

Fig. (1). Possible scheme of vitamin E functions. The solid arrows denote the possible locations by which vitamin E may exert its protective and/or attenuating effects. The blank arrows denote the formation of ROS/RNS and their possible promoting and/or modulating effects on cellular events. ETS stands for electron transport system/chain; Fe-protein stands, iron- protein complex; [Fe], free or unbound iron; GSH, reduced glutathione; SOD, superoxide dismutases; Se-GSH-Px; Selenium-GSH peroxidases; NO, nitric oxide, $\mathrm{ONOO}^{-}$, peroxynitrite; OH; hydroxyl radicals; CVD, cardiovascular disease.

\section{HEALTH IMPLICATIONS OF VITAMIN E}

In the $80 \mathrm{~s}$, the scientific rationale and data obtained from earlier epidemiological and retrospective studies that show an inverse relation between vitamin $\mathrm{E}$ intake risk of cardiovascular disease and cancer fueled a renew interest in the health benefit of the vitamin. However, a number of subsequent prospective randomized placebo-controlled interventional trials have failed to verify a consistent benefit [10-17]. In 1988, the U.S. Surgeon General's Report on Nutrition and Health summarized that there was no link between vitamin $\mathrm{E}$ levels and risk of cancer when incidence rates at all sites were combined. The U.S. National Research Council's Committee on Diet and Health concluded that vitamin E intake was not related to overall risk of cancer in 1989. In its 2000 Report on Antioxidants the U.S. Institute of Medicine concluded that "available data do not adequately substantiate the premise that increasing vitamin $\mathrm{E}$ intake will reduce the risk of coronary heart disease."

Based on the totality of available scientific evidence, the U.S. Food and Drug Administration concluded that "the weight of the evidence against the relationship is greater than the weight of evidence for the relationship," and denied a health claim relating to vitamin E supplement and reduced risk of cancer or cardiovascular disease for food labeling [17]. Also, the Panel on Dietary Antioxidants of the U.S. Food Nutrition Board did not recommend an increase in the daily allowance of vitamin $\mathrm{E}$. In addition to the inconclusive findings from prospective placebo-controlled trials, a lack of understanding on the mode of action of vitamin $\mathrm{E}$ at the tissue level is also responsible. Similarly, Vivekananthan et al. [66] have shown that meta analysis of data obtained from randomized trials fails to show prevention of antioxidant vitamins against cardiovascular disease.

Despite the inconsistent findings, the 2000 report of the U.S. National Academy of Sciences on Antioxidant Intake \& Disease Protection concluded that the information contains an abundance of positive information and commentary about antioxidants, disease prevention and safe range of intake, and recommended full-scale intervention trials to test the preventive potential of vitamins $\mathrm{C}$ and $\mathrm{E}$, selenium and carotenoids for disease. Partly due to this recommendation, several large-scale interventional trails dealing with antioxidants and disease risk supported by U.S. federal agencies were launched. The results available from several such studies have yielded some controversial findings.

In the Women's Health Study conducted between 1992 and 2004, 39876 healthy US women aged over 45 years were randomly assigned to receive vitamin E (600 IU on alternate days) or placebo and aspirin or placebo [67]. During an average of 10.1 years follow-up, there were no significant effects on the incidences major cardiovascular events, myocardial infarction or stroke, as well as ischemic 
or hemorrhagic stroke, although there was a significant $24 \%$ reduction for cardiovascular death. Also, there was no significant effect on the incidences of total cancer, or breast, lung, or colon cancers, or cancer mortality between groups. The data obtained indicate that $600 \mathrm{IU}$ vitamin $\mathrm{E}$ taken every other day provided no overall benefit for major cardiovascular events or cancer risk among healthy women.

Kirsh et al. [68] evaluated the association between intake of these micronutrient antioxidants and the risk of prostate cancer among men in the screening arm of the Prostate, Lung, Colorectal, and Ovarian Cancer Screening Trial. The Trial is a multicenter, randomized study that enrolled 29361 men aged 55-74 years who had no history of prostate, colon, or lung cancer. During up to 8 years of follow-up, they found that the age adjusted rate of advanced prostate cancer was 157 per 100,000 person-year among smokers who took vitamin E (400 IU daily) for 10 or more years, as compared to 492 per 100000 person-years of the controls. Among men with low dietary $\beta$-carotene intake, the age adjusted rate of prostate cancer was 1122 per 100000 person-years in the control group, compared to 623 in those who took at least $2000 \mu \mathrm{g} /$ day of supplemental $\beta$-carotene. These findings suggest that vitamin E supplementation in male smokers and $\beta$-carotene supplementation in men with low dietary $\beta$ carotene intakes were associated with reduced risk of this disease.

In the Physicians' Health Study II, a randomized, doubleblind, placebo-controlled factorial trial 14,641 US male physicians aged 50 years or older, including 754 men (5.1\%) with prevalent cardiovascular disease at randomization, received supplements of $400 \mathrm{IU}$ of vitamin E every other day and/or $500 \mathrm{mg}$ of vitamin C, or placebo daily [69]. During a mean follow-up of 8 years, there were 1245 confirmed major cardiovascular events, and compared with placebo, vitamin E had no effect on the incidence of major cardiovascular events, as well as total myocardial infarction, total stroke, and cardiovascular mortality. Also, there was no significant effect of vitamin $\mathrm{C}$ on major cardiovascular events, as well as total myocardial infarction, total stroke, and cardiovascular mortality. Additionally, neither vitamin E nor vitamin C had a significant effect on total mortality, but vitamin $\mathrm{E}$ was associated with an increased risk of hemorrhagic stroke. In a companion study that evaluates the effect of supplemental vitamins $\mathrm{E}$ and $\mathrm{C}$ on cancer risk of the subjects from the same Study, neither vitamin E nor vitamin $C$ supplement had a significant effect on the risk of prostate or total cancer [70]. These data do not support the supplemental use of vitamin E or vitamin $\mathrm{C}$ for the prevention of cardiovascular disease or cancer risk in middle-aged and older men.

In a recent report that has raised considerable media attention, Klein et al. [71] report data obtained from The Selenium and Vitamin E Cancer Prevention Trial (SELECT). The 122 million-dollar SELECT was launched after laboratory studies and some clinical data indicated that the antioxidant vitamin $\mathrm{E}$ and selenium might protect against prostate cancer, the second most common cancer and cancer killer in men. The results, however, show that men took 400 IU vitamin $\mathrm{E}$ had a significantly greater risk of developing prostate cancer. The primary analysis included 34,887 men aged 50 or older from 427 study sites in the United States, Canada, and Puerto Rico were randomly assigned to receive either selenium $(200 \mu \mathrm{g} / \mathrm{d})$, vitamin E $(400 \mathrm{IU} / \mathrm{d})$, both agents, or placebo for an average of 5.5 years, and an additional 1.5 years of follow-up. Compared with the placebo group in which 529 men developed prostate cancer, 620 men in the vitamin E group developed prostate cancer; 575 in the selenium group, and 555 in the selenium plus vitamin $\mathrm{E}$ group. This represents a 17 percent increase in prostate cancers relative to those who took a placebo. The findings suggest that vitamin E supplementation, but not along with selenium, may increase the risk of prostate cancer among healthy men.

In a recent report, Zhang et al. [72] analyzed data from a total of 132,837 individuals in China who were enrolled in two population-based cohort studies. They compared liver cancer risk among participants who had high intake of vitamin E with those with low intake. The analysis included 267 liver cancer patients (118 women and 149 men) who were diagnosed between 2 years after study enrollment and an average of 10.9 or 5.5 years of follow-up. Vitamin E intake from diet and vitamin E supplement use were both associated with a lower risk of liver cancer. This association was consistent among participants with and without self-reported liver disease or a family history of liver cancer. The findings suggest that high intake of vitamin $\mathrm{E}$ either from diet or supplements was related to lower risk of liver cancer.

In another highly publicized recent article, Fujita et al. [73] report that mice deficient in $\alpha$-tocopherol transfer protein (Ttpa-/- mice), a mouse model of genetic vitamin $\mathrm{E}$ deficiency, have high bone mass due to a decrease in bone resorption, and that wild-type mice or rats fed an $\alpha$ tocopherol-supplemented diet lost bone mass. The findings suggest that serum vitamin $\mathrm{E}$ is a determinant of bone mass through its regulation of osteoclast fusion, and that vitamin $\mathrm{E}$ supplements intended to reduce health risk may also cause thinning of bones. However, vitamin E supplements are known to interfere with the absorption and function of vita$\min \mathrm{K}$ and certain medications. As the dietary level of vita$\min \mathrm{E}(600 \mathrm{mg} \alpha$-tocopherol $/ \mathrm{kg}$ diet) employed in this study is way higher than that of vitamins $\mathrm{A}, \mathrm{D}$ and $\mathrm{K}$ (in $\mu \mathrm{g}$ ), it may impair the status and/or function of these nutrients.

Since most intervention trials reported involve more than one antioxidant and a follow-up period of less than 10 years, it is not surprising that those studies yielded inconsistent findings concerning the risk of cancer and cardiovascular diseases that take 20 or more years to develop. Also, it should be noted that the subjects in the interventional trials typically received $400 \mathrm{IU}$ vitamin $\mathrm{E}$ daily, which is almost 20 times as high as the Dietary Reference Intake of $22.4 \mathrm{IU}$ for adult recommended by the Food and Nutrition Board of the U.S. Institute of Medicine. Additionally, both natural and synthetic forms of vitamin $\mathrm{E}$ have been employed for interventional trials, they may or may not yield the same findings. Better long-term studies ( $>10$ years) specifically designed for vitamin $\mathrm{E}(<200 \mathrm{IU}$ daily) alone are needed to critically evaluate the association between the intake of this vitamin and the risk of chronic diseases in normal population. 


\section{SUMMARY AND CONCLUSION}

Vitamin $\mathrm{E}$ is the most important fat-soluble antioxidant, although its mode of action at the cellular or tissue levels has yet to be delineated. The antioxidant function of vitamin $\mathrm{E}$ is enhanced by GSH peroxidase and related metabolic systems. By attenuating the generation/levels of superoxide and unbound iron, dietary vitamin $\mathrm{E}$ may reduce the formation of reactive ROS/RNS and thus prevent oxidative damage. Also, it may modulate the activation and/or expression of redox-sensitive biological response modifiers and thereby modulate the cellular events leading to the onset and development of aging, cancer, cardiovascular disease and neurodegenerative disorders. Since the findings of prospective randomized placebo-controlled interventional trials have failed to provide a consistent benefit, no U.S. governmental agencies or professional associations have recommended supplementing vitamin $\mathrm{E}$ for health benefit. Available information suggests that lower doses of vitamin E supplement, when needed, are more appropriate.

\section{REFERENCES}

[1] Kamal-Eldin A, Appelqvist LA. The chemistry and antioxidant properties of tocopherols and tocotrienols. Lipids 1996; 31: 671701.

[2] Chow CK. Vitamin E. In: Rucker RB, Suttie JW, McCormick DB, Machlin LJ, Eds. Handbook of Vitamins, $3^{\text {rd }}$ ed. New York: Marcel Dekker 2001; pp. 165-97.

[3] Evans HM, Bishop KS. On the existence of a hitherto unrecognized dietary factor essential for reproduction. Science 1922; 56: 650-1.

[4] Scott ML. Studies on vitamin E and related factors in nutrition and metabolism. In: DeLuca HF, Suttie JW, Eds. The Fat-Soluble Vitamins. Madison: University of Wisconsin Press 1969; pp. 355-68.

[5] Bieri JG, Farrell PM. Vitamin E. Vit Horm 1976; 34: 31-75.

[6] Kohlschutter A, Hubner C, Jansen W, Lindner SG. A treatable familial neuromyopathy with vitamin E deficiency, normal absorption, and evidence of increased consumption of vitamin E. J Inher Metab Dis 1988; 11: 149-52.

[7] Arita M, Sato Y, Miyata AT, et al. Human $\alpha$-tocopherol transfer protein: gene structure and chromosomal localization. Biochem J 1995; 305: 437-43.

[8] Quahchi K, Arita M, Kayden HJ, et al. Ataxia with isolated vitamin E deficiency is caused by mutation in the $\alpha$-tocopherol transfer protein. Nat Genet 1995; 9: 141-5.

[9] Chow CK. Vitamin E and oxidative stress. Free Rad Biol Med 1991; 11: 215-32.

[10] Etminan M, Gill SS, Samii A. Intake of vitamin E, vitamin C, and carotenoids and the risk of Parkinson's disease: a meta-analysis. Lancet Neurol 2005; 4: 362-5.

[11] Pham DQ, Plakoqiannis R. Vitamin E supplementation in cardiovascular disease and cancer prevention: Part 1. Ann Pharmacother 2005; 39: 1870-8.

[12] Pham DQ, Plakoqiannis R. Vitamin E supplementation in Alzheimer's disease, Parkinson's disease, tardive dyskinesia, and cataract: Part 2. Ann Pharmacither 2005; 39: 2065-72.

[13] Lee IM, Cook NR, Gaziano JM, et al. Vitamin E in the primary prevention of cardiovascular disease and cancer: the Women's Health Study: a randomized controlled trial. J Am Med Assoc 2005; 294: 56-65.

[14] Eidelman RS, Hollar D, Hebert PR, Lamas GA, Hennekens CH. Randomized trials of vitamin $\mathrm{E}$ in the treatment and prevention of cardiovascular disease. Arch Int Med 2004; 164: 1552-6.

[15] Berman K, Brodaty H. Tocopherol [vitamin E] in Alzheimer's disease and other neurodegenerative disorders. CNS Drug 2004; 18: 807-25.

[16] Upston JM, Kritharides L, Stocker R. The role of vitamin E in atherosclerosis. Prog Lipid Res 2003; 42: 405-22.

[17] Jialal I, Devaraj S. Scientific evidence to support a vitamin E and heart disease health claim: research needs. J Nutr 2005; 135: 34853 .
[18] Trumbo PR. The level of evidence for permitting a qualified health claim: FDA's review of the evidence for selenium and cancer and vitamin E and heart disease. J Nutr 2005; 135: 354-56.

[19] Chow CK. Nutritional influence in cellular antioxidant defense systems. Am J Clin Nutr 1979; 32: 1066-81.

[20] Chow CK, Tappel AL. An enzymatic protective mechanism against lipid peroxidation damage to lungs of ozone-exposed rats. Lipids 1972; 7: 518-24.

[21] Chow CK. Effect of dietary vitamin E and selenium on rats: Pyruvate kinase, glutathione peroxidase and oxidative damage. Nutr Res 1990; 10: 183-94.

[22] Chow CK. Biochemical responses in the lungs of ozone-tolerant rats. Nature 1976; 260: 721-12.

[23] Chow CK, Tappel AL. Activities of pentose shunt and glycolytic enzymes in lungs of ozone-exposed rats. Arch. Environ. Health 1973; 26: 205-08.

[24] Chow CK, Reddy, K, Tappel AL. Effect of dietary vitamin E on the activities of glutathione peroxidase system in rat tissue. J Nutr 1973; 103: 618-624.

[25] Packer JE, Slater TF, Wilson RL. Direct observation of a free radical interaction between vitamin E and vitamin C. Nature 1979; 278 : 737-8.

[26] Diliberto E, Jr, Dean G, Carter C, Allen PL. Tissue, subcellular and submitochondrial distributions of semidehydroascorbaye reductase: possible role of semidehydroascorbate reductase in cofactor regeneration. J Neurochem 1982; 39: 563-8.

[27] Niki E, Tsuchiya J, Tanimura R, Kamiya Y. Regeneration of vitamin $\mathrm{E}$ from alpha-chromanoxy radical by glutathione and vitamin C. Chem Lett 1982; 789-92.

[28] Brigelius-Flohe R, Kelly FJ, Salonen JT, Neuzil J, Zingg JM, Azzi A. The European perspective on vitamin E: current knowledge and future research. Am J Clin Nutr 2002; 76: 703-16.

[29] Azzi A. Molecular mechanism of $\alpha$-tocopherol action. Free Rad Biol Med 2007; 43: 16-21.

[30] Niki E. Vitamin E function. Free-Rad Biol Med 2007; 43: 1466-67.

[31] Traber MG, Atkinson J. Vitamin E, antioxidant and nothing more. Free Rad Biol Med 2007; 43: 4-15.

[32] Yu BP. Cellular defense against damage from reactive oxygen species. Physiol Rev 1994; 74: 139-162.

[33] Indo HP, Davidson M, Yen HC, et al.: Evidence of ROS generation by mitochondria in cells with impaired electron transport chain and mitochondrial DNA damage. Mitochondrion; 2007; 7:106-18.

[34] Freeman BA, Crapo JD. Biology of disease: free radicals and tissue injury. Lab Invest 1982; 47: 412-26.

[35] Squadrito GL, Pryor WA: Oxidative chemistry on nitric oxide: The roles of superoxide, peroxynitrite, and cartbon dioxide. Free Rad Biol Med 1998; 25: 392-403.

[36] Buettner GR. Superoxide dismutase in redox biology: the roles of superoxide and hydrogen peroxide. Anticancer Agents Med Chem 2011:11:341-6.

[37] Wallace DC, Brown MD, Melov S, Graham B, Lott M. Mitochondrial biology, degenerative disease and aging. Biofactors 1998; 7 : $187-90$.

[38] Shigenaga, MK, Hagen TM Ames, BN. Oxidative damage and mitochondrial decay in aging. Proc Nat Acad Sci USA 1994; 91: 10771-8.

[39] Bjorneboe A, Nenseter MS, Hagen BF, Bjorneboe GE, Prydz K, Drevon CA. Effect of dietary deficiency and supplement with allrac-alpha-tocopherol on hepatic content in rats. J Nutr 1991; 121: 1208-13.

[40] Thomas PK, Cooper JM, King RH, et al. Myopathy in vitamin E deficient rats: muscle fiber necrosis associated with disturbances of mitochondrial function. J Anat 1993; 183: 451-61.

[41] Catignani GL, Chytil F, Darby WJ. Vitamin E deficiency: immunochemical evidence for increased accumulation of liver xanthine oxidase. Proc Nat Acad Sci USA 1974; 71: 1966-8.

[42] Masugi F, Nakamura T. Effect of vitamin E deficiency on the level of superoxide dismutase, glutathione peroxidase, catalase and lipid peroxide in rat liver. Internat J Vit Nutr Res 1976; 187-91.

[43] Chow CK, Ibrahim W, Wei Z, Chan AC. Vitamin E regulates mitochondrial hydrogen peroxide generation. Free Rad Biol Med 1999; 27: 580-7.

[44] Lass A, Sohal RS. Effect of coenzyme Q[10] and alpha-tocopherol content of mitochondria on the production of superoxide anion radicals. FASEB J 2000; 14: 87-94. 
[45] Chow CK. Vitamin E regulation of mitochondrial superoxide. Biol Signals Receptors 2001; 10: 112-124.

[46] Minotti G, Aust SD. The requirement for iron [III] in the initiation of lipid peroxidation by iron [II] and hydrogen peroxide. J Biol Chem 1987; 262: 1098-04.

[47] Afanas'ev IB. Superoxide and nitric oxide in pathological conditions associated with iron overload: the effects of antioxidants and chelators. Curr Med Chem 2005; 12: 2731-39.

[48] Emerit J, Beaumont C, Trivin F. Iron metabolism, free radicals, and oxidative injury. Biomed Pharmacother 2001; 55: 333-9.

[49] Kabat GC, Rohan TE. Does excess iron play a role in breast carcinogenesis? An unresolved hypothesis. Cancer Causes Control 2007; 18: 1047-53.

[50] Minotti G. Sources and role of iron in lipid peroxidation. Chem Res Toxicol 1993; 6: 134-6.

[51] Agrawal R, Sharma PK, Rao GS. Release of iron from ferritin by metabolites of benzene and superoxide radical generating agents. Toxicology 2001; 168: 223-30.

[52] Keyer K, Imlay JA. Superoxde accelerates DNA damage by elevating free iron levels. Proc Natl Acad Sci USA 1996; 93: 13635-40.

[53] Kakhlon O, Ioav Cabantchik Z. The labile iron pool: characterization, measurement, and participation in cellular processes. Free Rad Biol Med 2002; 33: 1037-46.

[54] Chou AC, Broun GO, Fitch CD Jr. Abnormalities of iron metabolism and erythropoieses in vitamin E-deficient rabbits. Blood 1978; 52: 187-95.

[55] Fraga CG, Oteiza P. Iron toxicity and antioxidant nutrients. Toxicology 2002; 180: 23-32.

[56] Ibrahim W, Chow CK. Dietary vitamin E reduces tissue labile iron. J Biochem Mol Toxicol 2005; 19: 298-303.

[57] Tucker JM, Townsend DM. Alpha-tocopherol: role in prevention and therapy of human disease. Biomed Pharmacother 2005; 59:380-7.

[58] Tasinato A, Boscoboinik D, Bartoli GM, Maroni P, Azzi A: DAlpha-tocopherol inhibition of vascular smooth muscle cell proliferation occurs at physiological concentrations, correlates with protein kinase $\mathrm{C}$ inhibition, and is independent of its antioxidant properties. Proc Natl Acad Sci USA 1995; 92: 12190-4.

[59] Ricci C, Pastukh V, Leonard J, Turrens J, Wilson G, Schaffer D, Schaffer SW. Mitochondrial DNA damage triggers mitochondrialsuperoxide generation and apoptosis. Am J Physiol Cell Physiol; 2008; 294:C413-22.
[60] Finkel T. Oxidant signals and oxidative stress. Curr Opin Cell Biol 2003; 5: 247-54.

[61] Holley AK, Bakthavatchalu V, Velez-Roman JM, St Clair DK. Manganese superoxide dismutase: guardian of the powerhouse. Int J Mol Sci; 2011;12:7114-46.

[62] Chiarugi P. Reactive oxygen species as mediators of cell adhesion. Ital J Biochem 2003; 52: 28-32.

[63] Shen HM, Liu ZG. JNK signaling pathway is a key modulator in cell death mediated by reactive oxygen and nitrogen species. Free Rad Biol Med 2006; 40; 928-39.

[64] Sylvester PW. Vitamin E and apoptosis. Vitam Horm 2007;76: 329-56.

[65] Linnane AW, Kios M, Vitetta L. Healthy aging: regulation of the metabolome by cellular redox modulation and prooxidant signaling systems: the essential roles of superoxide anion and hydrogen peroxide. Biogerontology 2007; 8:445-67.

[66] Vivekananthan DP, Penn MS, Sapp SK, Hsu A, Topol EJ. Use of antioxidant vitamins for the prevention of cardiovascular disease: meta-analysis of randomized trials. Lancet 2003; 361:2017-23.

[67] Lee IM, Cook NR, Gaziano JM, et al. Vitamin E in the primary prevention of cardiovascular disease and cancer: the Women's Health Study: a randomized controlled trial. J Am Med Assoc 2005;294: 56-65.

[68] Kirsh VA, Hayes RB, Mayne ST, et al. Supplemental and dietary vitamin $\mathrm{E}, \beta$-carotene, and vitamin $\mathrm{C}$ intakes and prostate cancer risk. J Natl Cancer Inst 2006; 98: 245-254.

[69] Sesso HD, Buring JE, Christen WG, et al. Vitamins E and C in the prevention of cardiovascular disease in men: the Physicians' Health Study II randomized controlled trial. J Am Med Assoc 2008; 300: 2123-33.

[70] Gaziano JM, Glynn RJ, Christen WG, et al. Vitamins E and C in the prevention of prostate and total cancer in men: the Physicians Health Study II randomized controlled trial. J Am Med Assoc 2009; 301: 52-62.

[71] Klein EA, Thompson IM, Tangen CM, et al. Vitamin E and the risk of prostate cancer: Results of the Selenium and Vitamin E Cancer Prevention Trial (SELECT). J Am Med Assoc 2011; 306: 1549-56.

[72] Zhang W, Shu XO, Li H, et al. Vitamin Intake and Liver Cancer Risk: A Report From Two Cohort Studies in China. J Nat Cancer Inst 2012 DOI: $10.1093 /$ jnci/djs277

[73] Fujita K, Iwasaki M, Ochi H, et al. Vitamin E decreases bone mass by stimulating osteoclast fusion. Nat Med 2012; Vol: 18: pp. 589594.

This is an open access article licensed under the terms of the Creative Commons Attribution Non-Commercial License (http://creativecommons.org/licenses/by-nc/3.0/) which permits unrestricted, non-commercial use, distribution and reproduction in any medium, provided the work is properly cited. 